\title{
Atraric acid, a marker for epiphytic lichens in the wood used in cooperage: Identification and quantification by $\mathrm{GC} / \mathrm{MS} /(\mathrm{MS})$
}

\author{
G. Bourgeois ${ }^{1, *}$, C. Suire ${ }^{2}$ and N. Vivas ${ }^{3}$ \\ technical collaboration: F. Benoist ${ }^{1}$ and C. Vitry ${ }^{1}$ \\ ${ }^{1}$ CESAMO, Université Bordeaux I, F-33405 Talence Cedex, France \\ ${ }^{2}$ IBGC-CNRS, 1 rue Camille Saint Saens, F-33077 Bordeaux Cedex, France \\ ${ }^{3}$ Tonnellerie Demptos, posted to CESAMO, Université Bordeaux I, F-33405 Talence Cedex, France
}

\begin{abstract}
A phenolic derivative, atraric acid, was identified by GC/MS and quantified by GC/MS/MS in the outer parts of wood from oaks specifically colonised by lichens. This compound was correlated to the presence of a bitter depside, atranorin, which is a natural metabolite of the lichen species belonging to the genus Parmelia.
\end{abstract}

Key words. Lichens - atranorin - atraric acid - oak wood - ion trap mass spectrometry - quantification.

\section{Introduction}

Wine or spirits are aged in barrels made with stave wood coming from the heartwood, mainly of two oak species: Quercus petraea (Mattusch.) Liebl. and Quercus robur L. Oaks used for cooperage activities are grown in regularly maintained forests in the centre of France and are felled between 150 and 250 years of age [1]. The bark of oaks is a support for different corticolous species, which have been listed [2]. Among the listed species, lichens are known to produce bitter depsides which could contaminate the bark and possibly the heartwood. Contaminated heartwood could induce off-flavour effects in the wines or spirits aged in such barrels and this is the reason for the interest of the cooperage industry in an estimate of the hazards related to the occurrence of bitter-producing organisms on the oak bark.

GC/MS analysis of acetone extracts from contaminated bark samples allowed us to identify the atraric acid $\underline{\mathbf{1}}$. GC/MS/MS analysis permits estimation of the quantity of compound $\underline{\mathbf{1}}$, the amounts of which decreased from the bark (not used in cooperage) to the outer heartwood normally used to make staves. Derivative $\underline{\mathbf{1}}$ has been related to the well known lichen product $\underline{\mathbf{2}}$ (atranorin), identified twenty years ago [3] in two of the lichen species that we have found on the bark of some trees.<smiles>CC(=O)c1c(C)cc(O)c(C)c1O</smiles>

$\underline{\mathbf{1}}$, atraric acid, $M=196$

benzoic acid, 2,4-dihydroxy-3,6-dimethyl-, methyl ester.

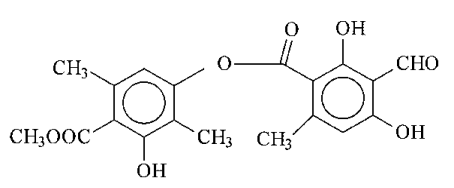

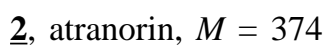

benzoic acid, 3-formyl-2,4-dihydroxy-6-methyl-, 3-hydroxy-4-(methoxycarbonyl)-2,5-dimethylphenyl ester.

\section{Materials and methods}

\section{Preparation of the extracts}

Outer part of the bark was carefully scraped to remove all the plants and especially lichens. Samples (1g dry weight) of cork, phloem, sapwood or heartwood were powdered to fine sawdust (60 Mesh) and extracted for 4 hours with $200 \mathrm{~mL}$ acetone using a "Soxhlet" apparatus. The solvent was evaporated under reduced pressure at $50{ }^{\circ} \mathrm{C}$ and the residue was recovered with $0.1 \mathrm{~mL}$ acetone. To quantify, $10 \mu \mathrm{L}$ acetone solution containing $1 \mathrm{~g} \mathrm{~L}^{-1}$ naphthalene were added to the wood powder, so that the final extract contained 10 ppm naphthalene.

\section{Hydrolysis of atranorin}

A solution of $1 \mathrm{mg}$ atranorin (A-6652 Sigma Aldrich Chemie, 89552-Steinheim, Germany) in $1 \mathrm{~mL}$ methanol was added to $1 \mathrm{~mL}$ water acidified $(\mathrm{pH} 2)$ by $\mathrm{HCl}$ and heated one day at $60{ }^{\circ} \mathrm{C}$. The reaction mixture was extracted by

\footnotetext{
* Correspondence and reprints.
}

Received November 17, 1998; revised January 22, 1999; accepted February 08, 1999. 


\section{Original articles}

diethyl ether. The extracted solution was dried over anhydrous sodium carbonate and directly injected into the GC/MS system.

\section{Identification of atraric acid, 1 , in extracts from the bark samples contaminated by lichens (Fig. 1) and in hydrolysate of atranorin (Fig. 2)}

Compound 1 was identified in GC/MS analysis by comparison of its spectrum with the reference spectrum of atraric acid listed in the NIST library [4], using a "SATURN 4D" (VARIAN INC. - Palo Alto - CA94304 - USA) ion trap mass spectrometer coupled to a VARIAN "Star 3400CX" gas chromatograph fitted with a "split-splitless" injector.

GC conditions: "DB XLB" (J\&W Scientific - Folsom - CA 95630 - USA, $30 \mathrm{~m} \times 0.25 \mathrm{~mm}$, film $0.25 \mu \mathrm{m}$ ) WCOT capillary column. Split mode. $1 \mu \mathrm{L}$ injection. Split rate: $1 / 50$. Temperature programmed from $50{ }^{\circ} \mathrm{C}$ to $300{ }^{\circ} \mathrm{C}$ $\left(4^{\circ} \mathrm{C} \mathrm{mn}-1\right.$ ). The DB XLB phase was chosen in reason of its low bleeding and its ability to separate a wide range of molecules of different boiling points.

MS conditions: Electron Impact $70 \mathrm{eV}$. Manifold temperature $220{ }^{\circ} \mathrm{C}$. Mass range 35-450 Daltons (100 scans $\mathrm{mn}^{-1}$ ).

\section{Detection and quantification of atraric acid (Fig. 3)}

$G C$ conditions: DB XLB J\&W, $30 \mathrm{~m} \times 0.25 \mathrm{~mm}$, film $\mu \mathrm{m}$ capillary column. Splitless mode. $1 \mu \mathrm{l}$ injection. Temperature programmed from $50{ }^{\circ} \mathrm{C}(1 \mathrm{~min})$ to $150{ }^{\circ} \mathrm{C}$ $\left(50{ }^{\circ} \mathrm{C} \mathrm{min}-1\right)$ and from $150{ }^{\circ} \mathrm{C}$ to $250{ }^{\circ} \mathrm{C}\left(12{ }^{\circ} \mathrm{C} \mathrm{min}-1\right)$.

MS conditions: mass spectra and mass chromatograms were successively recorded, during the same analysis, using the ion trap spectrometer in two different modes (Fig. 3):

- detection of the internal standard (naphthalene) performed by GC/MS in single ion monitoring of the molecular ion $\mathrm{m} / \mathrm{z} 128$.

- detection of the atraric acid performed by GC/MS/MS to improve the selectivity [5]. The molecular ion $(\mathrm{m} / \mathrm{z}$ 196) was isolated and fragmented by non-resonant collision induced dissociation (excitation amplitude $45 \mathrm{~V}$ isolation time $5 \mathrm{~ms}$ ). The intense daughter $\mathrm{m} / \mathrm{z}, 164$, resulting from the elimination of one molecule of methanol from the molecular ion $\mathrm{m} / \mathrm{z} 196$ was monitored during the chromatography.

The quantitative estimation of atraric acid was performed by comparison of the areas of the peaks corresponding to the daughter $m / z, 164$ in MS/MS mode and the peak corresponding to the molecular ion $\mathrm{m} / \mathrm{z}, 128$ of the naphthalene in direct mode. The calibration was done by running four reference acetone solutions, each containing $100 \mathrm{mg} \mathrm{L}^{-1}$ naphthalene and in addition $0.1,1,10$ or $100 \mathrm{mg} \mathrm{L}^{-1}$ atraric acid.

\section{Results and discussion}

A compound of molecular weight 196 was detected by GC/MS exclusively in the cork or in the sapwood of trunks
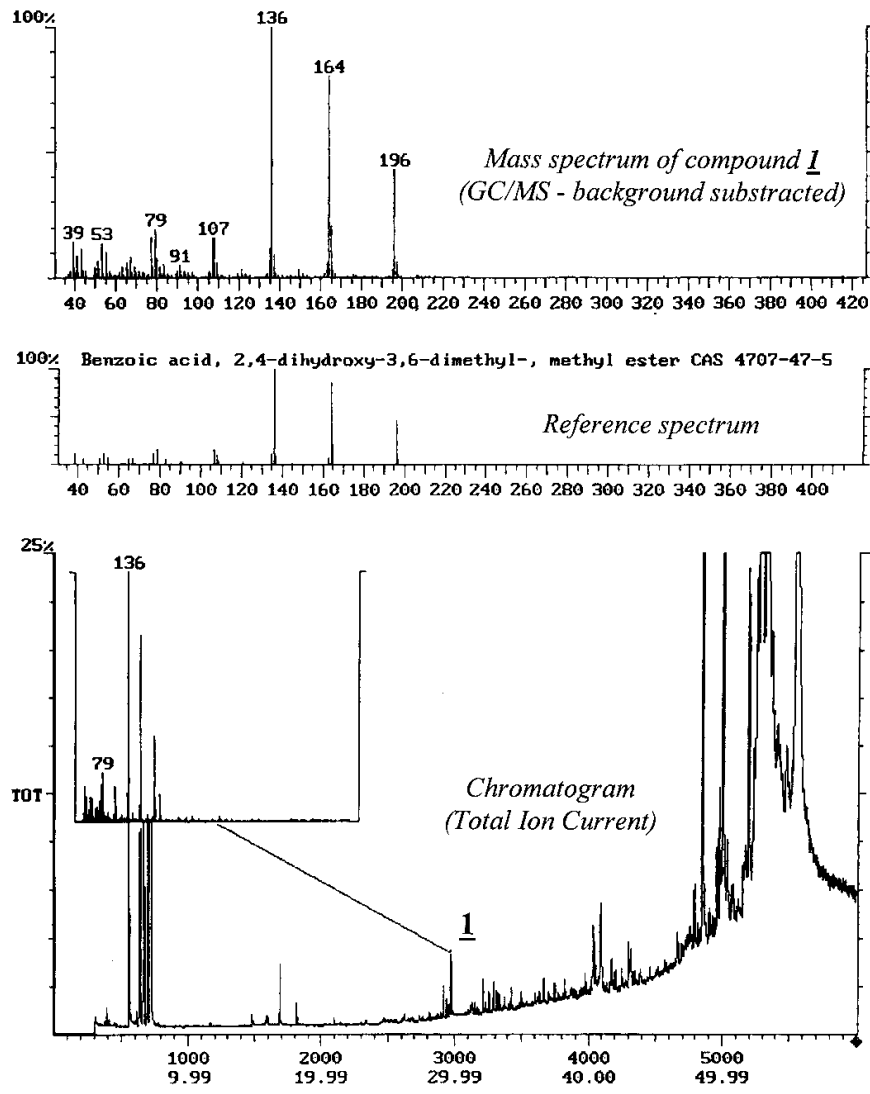

Fig. 1. Identification of atraric acid, $\underline{\mathbf{1}}$, in the extract from a bark sample contaminated by Parmelia olivetorum and P. perlata.

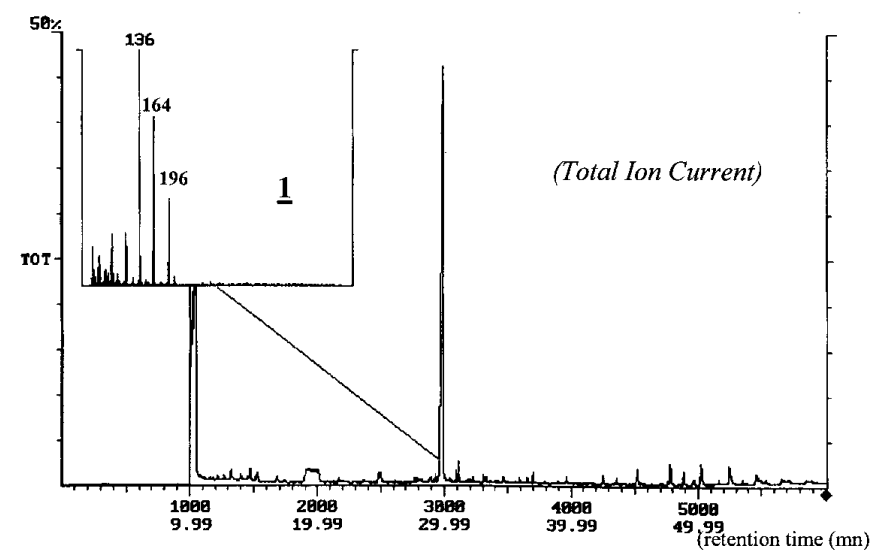

Fig. 2. Identification of atraric acid, $\mathbf{1}$, in the hydrolysate of atranorin, $\underline{\mathbf{2}}$, by GC/MS (total ion current and mass spectrum).

colonised by one at least of the two Parmelia species previously identified [2]: Parmelia olivetorum (Ach.) Nyl. and Parmelia perlata (Huds.) Ach. Both species as many others classified in the genus Parmelia or in some allied genera, produce the depside, atranorin, $\underline{\mathbf{2}}$ [3]. 


\section{Original articles}

The mass spectrum obtained by GC/MS was in good agreement with the reference spectrum of atraric acid, $\underline{\mathbf{1}}$, in the NIST library (Fig. 1) and with the spectrum obtained at the same retention time, by hydrolysis of atranorin, $\underline{\mathbf{2}}$ (Fig. 2). Atraric acid mass spectrum has three intense characteristic peaks: the molecular ion $(\mathrm{m} / \mathrm{z}$ 196), the peak resulting of the loss of methanol $(\mathrm{m} / z, 164)$ and the peak $(\mathrm{m} / \mathrm{z}, 136)$ resulting from elimination of $\mathrm{CO}$ from the last ion. Significant concentrations of $\underline{\mathbf{1}}$ were detected by GC/MS/MS (Fig. 3) only in cork $\left(10-100 \mu \mathrm{g} \mathrm{g}^{-1}\right.$ of sample) and in sapwood $\left(1 \mu \mathrm{g} \mathrm{g}^{-1}\right)$. In heartwood, the concentration in atraric acid did not exceed $0.001 \mu \mathrm{g} \mathrm{g}^{-1}$ (Fig. 4), which is the limit of detection. Atraric acid was not detected in cork samples taken off trunks without lichen or those with very small populations of lichens. Presence of atraric acid in the extracts of sapwood can obviously be correlated both to the occurrence of Parmelia olivetorum and/or P. perlata on the trunk of the tree and to the hydrolysis of the natural bitter depside atranorin: the tasteless derivative $\underline{\mathbf{1}}$ is an internal marker within the oak wood for the epiphytic Parmelia species.

The atraric acid or its precursor, the atranorin, did not diffuse deeper than the very outer heartwood (Fig. 4) and therefore did not significantly contaminate more than the outer staves in the case of an unusual strong colonisation of the bark by lichens; even in this unfavourable eventuality, few staves are likely to be contaminated and only very slightly. Such a contamination is presumed undetectable in the aged products.

\section{Conclusion}

Atraric acid, the hydrolysis product from the bitter atranorin, was found only in low concentrations in the heartwood used for staves and therefore its depside does not influence significantly the gustatory properties of wines or spirits aged in oak barrels. Nevertheless, it is advisable as an extra precaution, to avoid using for cooperage trees which are strongly colonised by Parmelia olivetorum and/or P. perlata, especially in the middle part of the trunk from which stave wood is taken.

\section{Acknowledgements}

This study was supported by the Conseil Régional d'Aquitaine and European grant FEDER.

\section{References}

1. Vivas, N. J. Cooperage Sci. Tech. 1995, 1, 33-48.

2. Suire, C.; Vivas, N.; Bourgeois, G. J. Cooperage Sci. Tech. 1996, 2, 113-119.

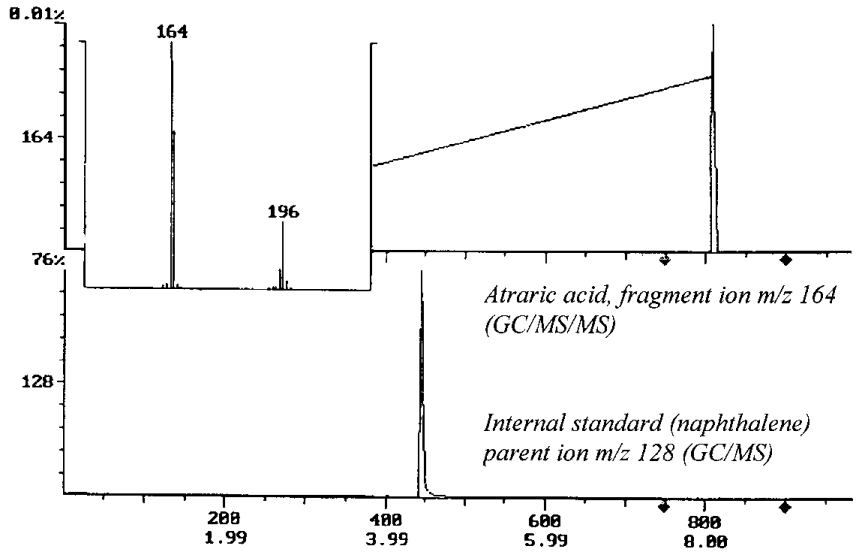

Fig. 3. Quantification of atraric acid, 1 (concentration measured: $0.9 \mu \mathrm{g} \mathrm{g}^{-1}$ of sapwood) by GC/MS/MS, using the naphthalene as internal standard.

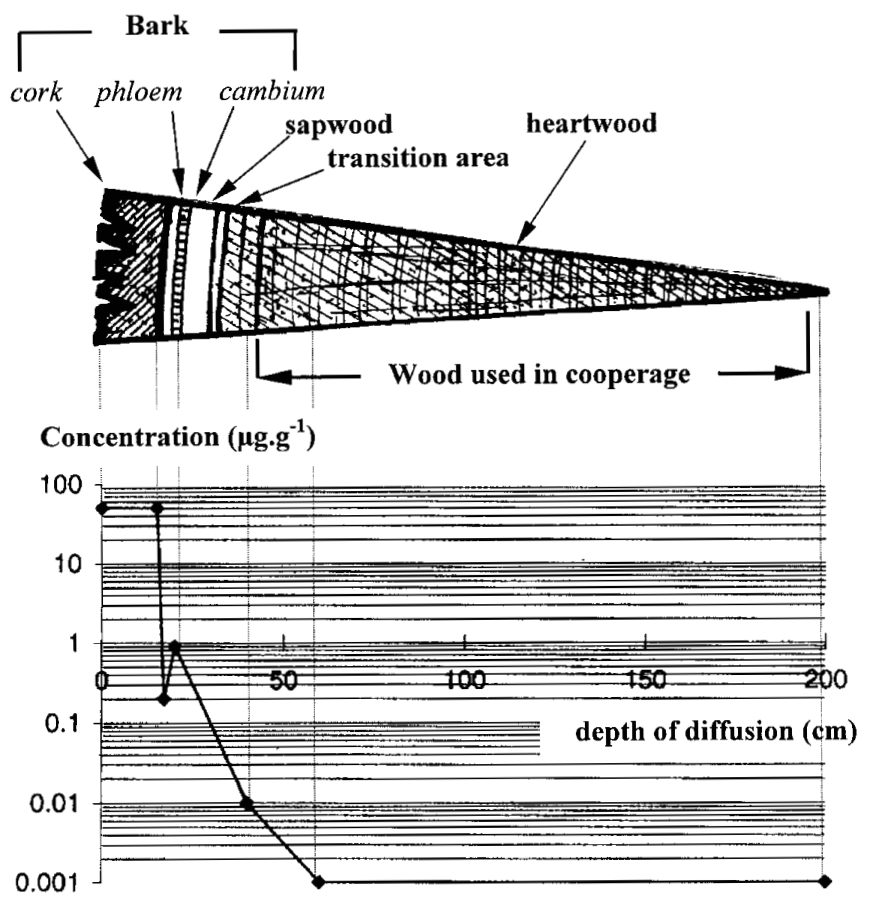

Fig. 4. Plot of the concentration in atraric acid, $\underline{\mathbf{1}}$, according to the diffusion depth in the wood.

3. Taylor, C. J. Ohio Biol. Surv., Biol. Notes (1967) In: Culberson C.F. The Bryologist 1970, 73, 177-377.

4. NIST/EPA/NIH Mass Spectral Database, Version 4.0, US Department of Commerce, Gaithesburg, USA (1992).

5. David, F.; De Clercq, C.; Sandra, P. VARIAN INC. Palo Alto, USA, Application note $\mathrm{N}^{\circ} 52$. 